\title{
On the Structure of the Grystal Form $A^{\prime}$ of $n$-Pentadecanoic Acid
}

\author{
By ERIK von Sydow \\ Institute of Chemistry, University of Uppsala, Uppsala, Sweden
}

(Received 31 March 1954)

\begin{abstract}
Form $A^{\prime}$ of $n$-pentadecanoic acid, $\mathrm{C}_{14} \mathrm{H}_{29} \mathrm{COOH}$, is triclinic with $a=4.25 \AA, b=5.01 \AA, c=$ $42.76 \AA ; \alpha=89^{\circ} 50^{\prime}, \beta=111^{\circ} 5^{\prime}, \gamma=112^{\circ} 10^{\prime}$.

The cell contains two molecules. The crystal shows no piezo-electric effect, indicating space group $C_{i}^{1}-P \overline{\mathbf{1}}$. Fourier projections along the shortest axis were prepared. The packing of the hydrocarbon chains is triclinic, all the chain-planes being parallel. The planes are slightly twisted helically.
\end{abstract}

\section{Introduction}

As a continuation of a work by Stenhagen \& von Sydow (1953) on the phase transitions in normal fatty acids it became necessary to study the different crystal forms in more detail to find the principal differences between them. Except for a great number of papers concerning long spacing, most of which are mentioned in the paper above, there have been few unit-cell determinations with X-rays: Müller (1927) ( $B$ form of stearic acid), Brill \& Meyer (1928) ( $C$ form of lauric acid), Thibaud $\&$ Dupré la Tour (1932) ( $C$ form of palmitic acid and $B$ form of stearic acid); and with electron diffraction: Trillat \& v. Hirsch (1932) (the smallest axis-plane of each of three forms of stearic acid).

The first workers to use Fourier techniques on these compounds were Vand, Morley \& Lomer (1951) in the determination of the structure of form $C$ of lauric acid.

The unit-cell data from all these investigations can probably be derived from the unit-cell data of the orthorhombic packing of hydrocarbon chains determined by Bunn (1939) and Vainshtein \& Pinsker (1950). In this packing the planes of alternate chains are almost perpendicular to each other.

This structure determination is the first Swedish contribution to this field and it will be followed by others at present in progress.

\section{Preparation of crystals}

The very pure specimen of $n$-pentadecanoic acid, $\mathrm{C}_{14} \mathrm{H}_{29} \mathrm{COOH}$, obtained from Prof. E. Stenhagen and his collaborators, had a melting point of $52 \cdot 3^{\circ} \mathrm{C}$. compared with $52 \cdot 26^{\circ} \mathrm{C}$. and $52 \cdot 1^{\circ} \mathrm{C}$, according to Meyer \& Reid (1933) and Francis, Piper \& Malkin (1930), respectively.

According to Stenhagen \& von Sydow (1953) the form $A^{\prime}$ of $n$-pentadecanoic acid is formed when crystallized from light petroleum and (together with form $B^{\prime}$ ) from glacial acetic acid. With these solvents, however, the crystals formed are much too small and not very uniform. In addition to these solvents the

A C 7 following were tried under different conditions: benzene, toluene, pentane, hexane, heptane, ethanol, carbon disulfide, carbon tetrachloride, ethyl ether and benzyl alcohol. Carbon tetrachloride gave the best crystals of form $A^{\prime}$, although they were not very large.

\section{Optical studies of crystals}

The crystals were rod-shaped with almost rectangular cross-section. The extinction in polarized light was very distinct and no twin formation could be seen under the microscope. The crystals were found to be biaxial with positive character. It was very helpful to know the direction of the acute bisectrix, i.e. the direction of the chains, when the crystals were later mounted for X-ray work. The crystals used for this purpose were cut from a rod, the cross-section of which had the dimensions $0.08 \times 0.05 \mathrm{~mm}$.

\section{X-ray data}

Rotation photographs about the $a$ and $b$ axes and zeroand $n$-layer Weissenberg photographs about the $a$ axis, were taken, using $\mathrm{Cu} K$ radiation from a gas tube and a calibrated camera. The following data were obtained:

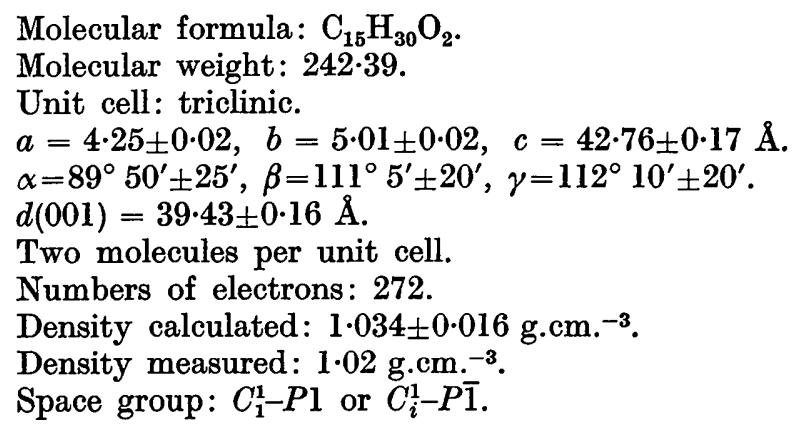

The absence of piezo-electric effect ( $\mathrm{I}$ am indebted to $\mathrm{Mr}$ J. Baecklund for help with the measurements) indicates space group $C_{i}^{1}-\bar{P} \overline{1}$, which has a centre of symmetry.

No twinning was observed. 


\section{Conclusions from the unit cell}

If the unit-cell data are compared with the data of the triclinic subcell in trilaurin (Vand \& Bell, 1951) some interesting similarities will be seen. The triclinic subcell in question has the following data:

$$
\begin{aligned}
& a_{s}=4 \cdot 287, b_{s}=5 \cdot 40, c_{s}=2 \cdot 45 \AA ; \\
& \alpha_{s}=74^{\circ} 45^{\prime}, \beta_{s}=108^{\circ} 2^{\prime}, \gamma_{s}=117^{\circ} 24^{\prime} .
\end{aligned}
$$

In Fig. 1 the two cells are placed with their $c$ axes

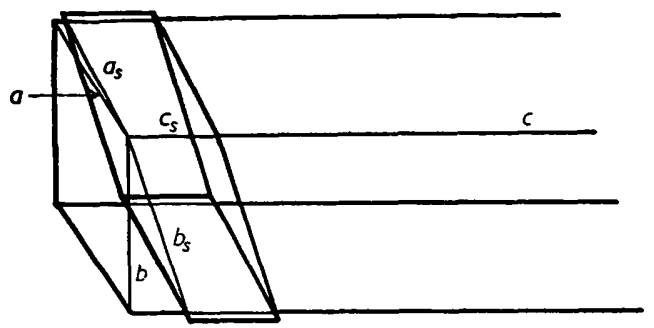

Fig. 1. Part of the main cell and the triclinic subcell.

and $b c$ planes coincident. The $a$ axes will then coincide approximately. The distance in the main cell along $b_{s}$,

$$
b_{s}^{\prime} \sim b / \cos \left(\alpha-\alpha_{s}\right) \sim 5 \cdot 20 \AA,
$$

is rather close to $b_{s}$. From these facts one can conclude with some certainty that the $A^{\prime}$ form of $n$-pentadecanoic acid has the same triclinic packing of the hydrocarbon chains as trilaurin.

\section{Structure factors and electron-density projection}

Owing to the smallness of the available crystal rather few reflexions were registered: with a $120 \mathrm{hr}$. exposure there were only $38(0 \mathrm{kl})$ reflexions.

Two observers estimated the intensities by eye, using the multiple-film technique of de Lange, Robertson \& Woodward (1939). The strongest reflexion was 250 times stronger than the weakest one observed. The intensities were corrected with the normal polarization and Lorentz factors. No absorption corrections were applied. A set of relative, observed structure factors were calculated. These were later brought on an absolute scale by comparison with calculated structure factors.

For the first calculation of structure factors atomic coordinates were taken from the triclinic subcell in trilaurin (Vand \& Bell, 1951). The subcell theory for long-chain compounds, first suggested by Müller (1927) and later developed by Vand (1951) and used by Vand \& Bell (1951), was used here. At this stage the $\mathrm{CH}_{2}$ groups were considered as single atoms with $f=f_{\mathrm{C}}+2 f_{\mathrm{H}}$. The carboxylic group was given probable coordinates.

Atomic scattering factors were taken from Mc Weeny (1951), using - for oxygen $f=\frac{1}{3}\left(f^{\perp}+2 f^{\|}\right)$and for carbon the values for 'valence states'.

For the Fourier summation both Beevers-Lipson strips $\left(3^{\circ}\right)$ and a machine designed by Hägg \& Laurent (1946) were used.

Successive electron-density projections along the shortest axis were prepared, alternating with structurefactor calculations. The first summation was made with only 18 structure factors and gave a remarkably good resolution. This is of course due to the periodicity in the hydrocarbon chains.

In the later structure-factor calculations the carbon and hydrogen atoms were separated. The coordinates of the two hydrogen atoms relative to the corresponding carbon atom were determined from data given by Vainshtein \& Pinsker (1950). As both hydrogen atoms had about the same $y$ and $z$ coordinates they were placed on the centre of gravity and considered as one atom having $f=2 f_{\mathrm{H}}$.

From the sixth projection (Fig. 2) it can be seen that the chains are not planar. The carbon atoms are still lying on two straight lines, which now, however, diverge. As the distance between the carbon atoms in each row in the projection is constant, within experimental error, the subcell theory can still be applied, but two different subcell regions must be considered, each representing one row of carbon atoms with their hydrogen atoms.

The last structure-factor calculation was carried out with data from the projection in Fig. 2 and the oxygen

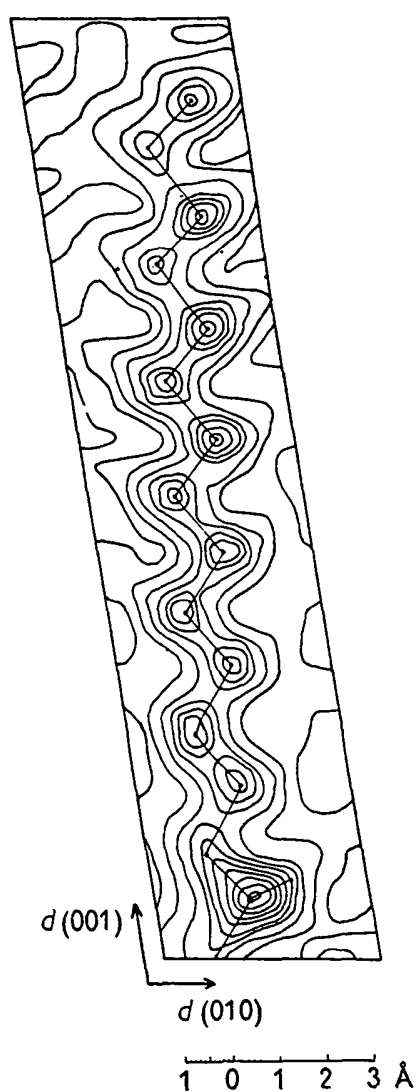

Fig. 2. Electron-density projection along the $a$ axis. 
Table 1. Co-ordinates of the atoms

\begin{tabular}{|c|c|c|c|c|c|}
\hline Atom & $y / b$ & $z / c$ & Atom & $y / b$ & $z / c$ \\
\hline $\mathrm{O}_{1} \mathrm{H}_{1}$ & 0.265 & 0.002 & $\mathrm{H}_{2}+\mathrm{H}_{3}$ & $0 \cdot 129$ & 0.060 \\
\hline $\mathrm{C}_{1}$ & 0.450 & 0.0320 & $\mathrm{H}_{4}+\mathrm{H}_{5}$ & 0.651 & 0.093 \\
\hline $\mathrm{O}_{2}$ & 0.630 & 0.046 & $\mathrm{H}_{6}+\mathrm{H}_{7}$ & 0.171 & 0.123 \\
\hline $\mathrm{C}_{2}^{4}$ & $0 \cdot 277$ & 0.0562 & $\mathrm{H}_{8}+\mathrm{H}_{9}$ & 0.697 & $0 \cdot 153$ \\
\hline $\mathrm{C}_{3}$ & $0 \cdot 496$ & 0.0926 & $\mathrm{H}_{10}^{\circ}+\mathrm{H}_{11}$ & 0.213 & $0 \cdot 185$ \\
\hline $\mathrm{C}_{4}^{\circ}$ & $0 \cdot 318$ & 0.1188 & $\mathrm{H}_{12}+\mathrm{H}_{13}$ & 0.743 & 0.214 \\
\hline $\mathrm{C}_{5}$ & 0.542 & $0 \cdot 1532$ & $\mathrm{H}_{14}^{14}+\mathrm{H}_{15}$ & 0.255 & 0.248 \\
\hline $\mathrm{C}_{6}$ & $0 \cdot 360$ & $0 \cdot 1814$ & $\mathrm{H}_{16}+\mathrm{H}_{17}$ & 0.789 & 0.274 \\
\hline $\mathrm{C}_{7}$ & 0.588 & 0.2138 & $\mathrm{H}_{18}+\mathrm{H}_{19}$ & 0.297 & $0 \cdot 310$ \\
\hline $\mathrm{C}_{8}$ & 0.402 & $0 \cdot 2439$ & $\mathrm{H}_{20}+\mathrm{H}_{21}$ & 0.835 & 0.335 \\
\hline $\mathrm{C}_{9}^{\circ}$ & 0.634 & 0.2743 & $\mathrm{H}_{22}+\mathrm{H}_{23}$ & 0.339 & 0.373 \\
\hline $\mathrm{C}_{10}$ & 0.444 & 0.3065 & $\mathrm{H}_{24}+\mathrm{H}_{25}$ & 0.882 & 0.396 \\
\hline $\mathrm{C}_{11}$ & 0.681 & 0.3349 & $\mathrm{H}_{26}+\mathrm{H}_{27}$ & $0 \cdot 381$ & 0.435 \\
\hline $\mathrm{C}_{12}$ & 0.486 & 0.3691 & $\mathrm{H}_{28}+\mathrm{H}_{29}$ & 0.928 & 0.456 \\
\hline $\mathrm{C}_{13}$ & $0 \cdot 727$ & $0 \cdot 3955$ & $\mathrm{H}_{30}^{\circ}$ & 0.634 & 0.482 \\
\hline$C_{14}$ & 0.528 & 0.4317 & & & \\
\hline $\mathrm{C}_{15}$ & 0.773 & & & & \\
\hline
\end{tabular}

atoms were moved until the best resemblance to observed structure factors was obtained. No new signs were obtained. The atomic coordinates are collected in Table 1 and observed and calculated structure factors in Table 2 . The reliability index $R=$ $\Sigma\left|F_{o}-F_{c}\right| \div \Sigma\left|F_{o}\right|$ is $0 \cdot 21$.

\section{Discussion of the results}

As has been pointed out already, no twinning has been observed. This is remarkable as this effect seems to be very common among the fatty acids and also among other long-chain compounds (see for instance Müller (1927) and Stenhagen, Vand \& Sim (1952)).

As pointed out by Vand \& Bell (1951), the triclinic packing of hydrocarbon chains with all chain-planes parallel, which appears in this crystal form and in trilaurin, also appears in the low-temperature form of hydrocarbons described by Müller \& Lonsdale (1948) and in silver soaps described by Vand, Aitken \& Campbell (1949). The difference in the dimensions of the smallest axis-plane is partly due to the chain length and partly to the nature of the end group.

The increment of long spacing for this crystal form, according to Stenhagen \& von Sydow (1953), is $2 \cdot 39 \AA$. Thus the angle of tilt is between $71^{\circ}$ and $66^{\circ}$ if the distance between alternate carbon atoms has a value between $2.521 \AA$, found in lauric acid by Vand, Morley \& Lomer (1951), and $2 \cdot 610 \AA$, found in strontium laurate by Morley \& Vand (1949).

From the electron-density map shown in Fig. 2 it can be seen that the chains are not planar.* The plane is probably helically twisted round the centreline of the chain. The centreline may be somewhat bent, too, in that case in a direction perpendicular to the chain plane. In the projection one can also see that the thermal motion is bigger in the end of the hydrocarbon chain than in the carboxylic group, which is held more tightly with hydrogen bonds.

* This is probably not an effect due to series termination as the projection proceeding the last one did not show this effect, having the rows of carbon atoms approximately parallel.

Table 2. Observed and calculated structure factors

$\begin{array}{rrr}h k l & \left|F_{o}\right| & F_{c} \\ 000 & 272 & \\ 001 & 30 \cdot 7 & 33 \cdot \\ 002 & 5 \cdot 9 & 6 \\ 003 & 25 \cdot 6 & 28 \\ 004 & <4 \cdot 9 & 0 \cdot \\ 005 & 16 \cdot 4 & 20 \cdot \\ 006 & <6 \cdot 0 & -7 \cdot \\ 007 & 6 \cdot 5 & 12 \cdot \\ 008 & 8 \cdot 9 & -12 \cdot \\ 009 & <7 \cdot 4 & 5 \cdot \\ 0,0,10 & 9 \cdot 7 & -16 \cdot \\ 0,0,11 & <8 \cdot 3 & 4 \cdot \\ 0,0,12 & 13 \cdot 8 & -15 \cdot 8 \\ 0,0,13 & <9 \cdot 1 & 4 \cdot \\ 0,0,14 & 14 \cdot 4 & -15 \cdot \\ 0,0,15 & <10 \cdot 0 & 0 \cdot 1 \\ 0,0,16 & 11 \cdot 6 & 12 \cdot \\ 0,0,17 & <10 \cdot 9 & -0 \cdot \\ & & \\ 010 & 116 \cdot 6 & -107 \cdot 9 \\ 011 & 18 \cdot 5 & -14 \cdot \\ 012 & 32 \cdot 4 & -24 \cdot \\ 013 & 14 \cdot 5 & -6 \cdot \\ 014 & 10 \cdot 9 & -7 \cdot 8 \\ 015 & <8 \cdot 2 & -5 \cdot 7 \\ 016 & <8 \cdot 4 & -3 \cdot 9 \\ 017 & <8 \cdot 6 & -4 \cdot 9 \\ 018 & <8 \cdot 9 & -3 \cdot 4 \\ 019 & <9 \cdot 2 & -3 \cdot 5 \\ 0,1,10 & <9 \cdot 5 & -4 \cdot \cdot \\ 0,1,11 & <9 \cdot 8 & -1 \cdot \\ & & \end{array}$

\begin{tabular}{r|}
$F_{c}$ \\
\hline $3 \cdot 2$ \\
$6 \cdot 1$ \\
$28 \cdot 3$ \\
$0 \cdot 0$ \\
$20 \cdot 4$ \\
$-7 \cdot 1$ \\
$12 \cdot 1$ \\
$-12 \cdot 5$ \\
$5 \cdot 0$ \\
$-16 \cdot 0$ \\
$4 \cdot 2$ \\
$-15 \cdot 8$ \\
$4 \cdot 4$ \\
$-15 \cdot 3$ \\
$0 \cdot 1$ \\
$12 \cdot 2$ \\
$-0 \cdot 4$ \\
$-107 \cdot 9$ \\
$-14 \cdot 6$ \\
$-24 \cdot 3$ \\
$-6 \cdot 0$ \\
$-7 \cdot 8$ \\
$-5 \cdot 7$ \\
$-3 \cdot 9$ \\
$-4 \cdot 9$ \\
$-3 \cdot 4$ \\
$-3 \cdot 5$ \\
$-4 \cdot 1$ \\
$-1 \cdot 9$ \\
\hline
\end{tabular}

\begin{tabular}{|c|c|c|}
\hline$h k l$ & $\left|F_{0}\right|$ & $F_{c}$ \\
\hline $0,1,12$ & $<10.2$ & -2 \\
\hline $0,1,13$ & $<10.5$ & $2 \cdot 9$ \\
\hline $0,1,14$ & $<10.9$ & $-11 \cdot 0$ \\
\hline $0,1,15$ & $50 \cdot 8$ & \\
\hline $0,1,16$ & $24 \cdot 1$ & 3 \\
\hline $0,1,17$ & 20.8 & -2 \\
\hline $01 \overline{1}$ & $44 \cdot 3$ & -30 . \\
\hline $01 \overline{2}$ & $75 \cdot 1$ & \\
\hline $01 \overline{3}$ & $<7.3$ & -9 \\
\hline $01 \underline{\overline{4}}$ & $24 \cdot 3$ & 20 \\
\hline $01 \overline{5}$ & $<7.7$ & - \\
\hline $01 \underline{6}$ & $13 \cdot 8$ & 13 \\
\hline $01 \overline{7}$ & $<8.0$ & -5 \\
\hline $01 \underline{8}$ & $16 \cdot 1$ & 12 \\
\hline $01 \underline{\overline{9}}$ & $<8.6$ & - \\
\hline $0,1, \overline{10}$ & $17 \cdot 2$ & 12 \\
\hline $0,1, \overline{1} \overline{1}$ & $9 \cdot 2$ & 6 \\
\hline $0,1, \overline{12}$ & 19.9 & 12 \\
\hline $0,1, \overline{13}$ & $9 \cdot 8$ & \\
\hline $0,1,14$ & $19 \cdot 1$ & I \\
\hline $0,1,15$ & $12 \cdot 4$ & 10 \\
\hline $0,1, \overline{1} \mathbf{6}$ & $26 \cdot 7$ & -35 \\
\hline $0,1, \overline{17}$ & $67 \cdot 5$ & \\
\hline 020 & $<11 \cdot 1$ & - \\
\hline 021 & $<11.3$ & \\
\hline 022 & $<11.4$ & \\
\hline 023 & $<11.5$ & \\
\hline 024 & $<11 \cdot 7$ & - \\
\hline 025 & $<11.8$ & \\
\hline
\end{tabular}

$h k l$
026
027
028
029
$0,2,10$
$0,2,11$
$0,2,12$
$0,2,13$
$0,2,14$
$0,2,15$
$0 \cdot 2 \cdot 16$

$02 \overline{1}$
$02 \overline{2}$
$02 \overline{3}$
$02 \overline{4}$
$02 \overline{5}$
$02 \overline{6}$
$02 \overline{7}$
$02 \overline{8}$
$02 \overline{9}$
$0,2, \overline{10}$
$0,2, \overline{11}$
$0,2, \overline{12}$
$0,2, \overline{13}$
$0,2, \overline{14}$
$0,2, \overline{15}$
$0,2, \overline{16}$
$0,2, \overline{17}$
$0,2, \overline{1} \overline{8}$
$0,2, \overline{19}$

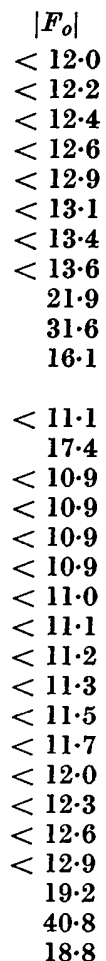

$\boldsymbol{F}_{\boldsymbol{c}}$ 
I am most thankful to Dr V. Vand, who taught me the fundamentals of this sort of work, and to Prof. G. Hägg and Prof. E. Stenhagen for their advice and interest. Mr S. E. Flygar has carried out much of the computations and I am indebted to him for his careful work.

\section{References}

BRIIL, R. \& MEYER, K. H. (1928). Z. Kristallogr. 67, 570.

Bunn, C. W. (1939). Trans. Faraday Soc. 35, 482.

Francis, F., Piper, S. H. \& Malikin, T. (1930). Proc. Roy. Soc. A, 128, 214.

HäGG, G. \& LAURENT, T. (1946). J. Sci. Instrum. 23, 155.

Lange, J. J. DE, Robertson, J. M. \& Woodward, I. (1939). Proc. Roy. Soc. A, 171, 398.

McWeeny, R. (1951). Acta Cryst. 4, 513.

Meyer, J. D. \& Reid, E. E. (1933). J. Amer. Chem. Soc. 55,1574 .

Acta Cryst. (1954). 7, 532
Morley, W. M. \& VAND, V. (1949). Nature, Lond. 163, 285.

Müller, A. (1927). Proc. Roy. Soc. A, 114, 542.

MÜller, A. \& Lonsdale, K. (1948). Acta Cryst. 1, 129.

Stenhagen, E. \& Sydow, E. von (1953). Arkiv Kemi, $6,309$.

Stenhagen, E., VAND, V. \& Sim, A. (1952). Acta Cryst. 5,695 .

Thibaud, J. \& DUPRÉ LA Tour, F. (1932). J.Chim.Phys. 29, 164.

Trimlat, J.J. \& Hirsch, Th. v. (1932). C. R. Acad. Sci., Paris, 195, 215.

Vainshtein, B. K. \& Pinsker, Z. G. (1950). Dokl. Akad. Nauk, SSSR. 72, 53.

VAND, V. (1951). Acta Cryst. 4, 104.

Vand, V., Aitken, A. \& Campbell, R. K. (1949). Acta Cryst. 2, 398.

VAND, V. \& BeLl, I. P. (195I). Acta Cryst. 4, 465.

VAND, V., MORLEY, W. M. \& LOMER, T. R. (1951). Acta Cryst. 4, 324.

\title{
The Grystal Structure of Samarium*
}

\author{
By A. H. Daane, R. E. Rundle, H. G. Smith and F. H. Spedding \\ Institute for Atomic Research and Department of Chemistry, Iowa State College, Ames, Iowa, U.S.A.
}

(Received 25 September 1953 and in revised form 3 February 1954)

\begin{abstract}
The crystal structure of samarium is rhombohedral; $a=8.996 \AA, \alpha=23^{\circ} 13^{\prime}, Z=3$. The atomic positions are $0,0,0 ; \frac{2}{9}, \frac{2}{9}, \frac{2}{9}$; and $\frac{7}{9}, \frac{7}{9}, \frac{7}{9}$. Single-crystal data require a disordered (or submicroscopically twinned) structure where half of the unit cells are rotated $180^{\circ}$ about the threefold axis with respect to the other half. The hexagonal lattice constants are $a=3 \cdot 621 \pm 0 \cdot 007 \AA$, $c=26 \cdot 25 \pm 0 \cdot 05 \AA ; Z=9$.
\end{abstract}

\section{Introduction}

The method of preparation and the large, rhombohedral unit cell for samarium were reported recently by Daane, Dennison \& Spedding (1953). Single crystals showed clearly that some sort of disorder was present in the structure, and an investigation of the structure and nature of the disorder was made. Since the completion of this work a report of the structure derived from powder data has been published by Ellinger \& Zachariasen (1953). We report here a brief confirmation of the structure from single-crystal data, together with the nature of the disorder, which was not discovered from the powder data.

\section{Experimental data}

Weissenberg and precession photographs were taken

* Contribution No. 322 from the Institute for Atomic Research and Department of Chemistry, Iowa State College, Ames, Iowa. Work was performed in the Ames Laboratory of the Atomic Energy Commission. with $\mathrm{Cu} K \alpha$ and Mo $K \alpha$ radiation, respectively, using single crystals picked from a sample of $99 \%$ purity. Precession data, using small crystals and Mo radiation, indicated a Laue symmetry $D_{6 h}$.

The reflections were indexed on a hexagonal cell with lattice constants

$$
a=3 \cdot 621 \pm 0 \cdot 007 \AA, c=26 \cdot 25 \pm 0 \cdot 05 \AA .
$$

(These values were obtained from a precession photograph of $(h 0 . l)$ data with a calcite diffraction pattern superimposed on the film.) The observed bulk density is $7.53 \mathrm{~g} . \mathrm{cm} .^{-3}$, while the calculated X-ray density is 7.54 g.cm..$^{-3}$ assuming 9 atoms per unit cell.

The observed reflections may be divided into two types:

Type I: $(h k . l)$-for $h-k=3 n$, only with $l=9 n$;

Type II: $(h k . l)$-for $h-k \neq 3 n$, only with $l \neq 3 n$.

In addition it was observed that the intensities of reflections of Type I are the same, except for the normal decline due to reduced scattering power of the 